\title{
Construction of Farmland Solar Radiation DB Using GIS to Solve the Problem of Abandoned Cultivated Land and Select Cultivated Crops for AI
}

\section{Atsushi Shiota*, Thongchart Kerdphol and Yasunori Mitani}

Department of Electrical and Electronics Engineering, Kyushu Institute of Technology, Japan

*Corresponding Author: Atsushi Shiota, Department of Electrical and Electronics Engineering, Kyushu Institute of Technology, Japan.
Received: March 05, 2020

Published: April 09, 2020

(c) All rights are reserved by Atsushi

Shiota., et al.

\begin{abstract}
In Japan, abandoned cultivated lands have increased due to labor shortages caused by aging, low productivity, lack of farmland recipients, and poor land conditions. The increase of abandoned agriculture land causes problems such as a decline in the multifunctionality of agriculture, the occurrence of pests, birds, and animals. For this reason, the Japanese government has enacted legislation considering the measures to reduce or prevent the abandoned agriculture land. As a result, the area of abandoned agriculture lands was 423,000 ha in 2015 , and the rate of increase has slowed.
\end{abstract}

On the other hand, there is RUE (Radiation Use Efficiency) as a numerical value, representing the relationship between the amount of crop production and the amount of solar radiation. RUE is obtained by dividing the dry matter production amount by the accumulated light reception amount during the same period, and it is known that the dry matter production amount increases as the accumulated light reception amount increases, although there is a difference depending on the crop.

Our research team has constructed a solar radiation simulation system using GIS (Geographic Information System) and DSM (Digital Surface Model) considering the shadow of buildings and trees. As a result, it has become possible to support the selection of a place, where the amount of solar radiation falling on the solar power generation system can be efficiently obtained, and to understand how much solar radiation can be obtained when the solar power generation system is installed. In addition, it has been incorporated with the weather conditions into this simulation system. Finally, a solar radiation simulation considering the weather conditions is successfully built.

Based on these circumstances, this research focuses on the amount of solar radiation falling on farmland, and constructs a farmland solar radiation DB in consideration of the shadow of buildings and trees and weather conditions for each farmland. The purpose of this research is to visualize farmlands that can receive a large amount of solar radiation and to establish a mechanism to support prioritization during the selecting abandoned agriculture lands and supporting the reuse of abandoned agriculture lands. In addition, the farmland solar radiation DB is designed to build an farmland DB that can manage items such as precipitation, temperature and soil in addition to solar radiation, assuming a mechanism to be able to propose crops grown using AI(Artificial Intelligence) in the future.

Keywords: GIS (Geographic Information System); DSM (Digital Surface Model); RUE (Radiation Use Efficiency); Farmland; Weather Condition; Database

\section{Abbreviations}

GIS: Geographic Information System; DSM: Digital Surface Model; DEM: Digital Elevation Model; RUE: Radiation Use Efficiency; AI: Artificial Intelligence; NEDO: New Energy and Industrial Technology Development Organization

\section{Introduction}

In Japan, abandoned agriculture lands have increased due to labor shortages caused by aging, low productivity, lack of farmland recipients, and poor land conditions. In Japan, the abandoned agriculture land is a statistical term used to describe abandoned agriculture land, which is a statistical term that refers to "owned arable land that has not been cultivated for more than a year, and will not be cultivated again until several years in the future" [1]. The increase of abandoned agriculture land causes problems such as a decline in the multifunctionality of agriculture, occurrence of pests, birds, and animals. Therefore, the Japanese government has enacted laws. As a result, the Japanese government and local governments are implementing the following measures. 1. Support for the recycling of degraded farmland, 2. Support for efforts such as accumulating use for farmers, 3 . Support for efforts to facilitate the entry of companies, etc. 4. Support for use as a civic farm, 5. Support for grazing and increasing of feed and so on. As a result, the area of abandoned agriculture lands was 423,000 ha in 2015, and the rate of increase has slowed [2].

On the other hand, there is RUE as a numerical value representing the relationship between the amount of crop production and the amount of solar radiation. RUE is obtained by dividing the dry matter production amount $\mathrm{W}$ by the accumulated light reception amount Si during the same period. Further, Si is an integrated value during the period of the product of the daily solar radiation S0 and 
Our research team has constructed a solar radiation simulation system using GIS and DSM considering the shadow of buildings and trees. As a result, it has become possible to support the selection of a place, where the amount of solar radiation falling on the solar power generation system can be efficiently obtained, and to understand how much solar radiation can be obtained when the solar power generation system is installed [4]. In addition, it has been incorporated the weather conditions into this simulation system and constructed a solar radiation simulation considering the weather conditions [5].

In this research, it solves the problem on the agricultural field by applying the solar radiation simulation technology, that has been established in the electric energy field. It constructs a farmland solar radiation DB, that considers the shadows of buildings, trees, and weather conditions for each farmland focusing on the amount of solar radiation falling on its area.

\section{Purpose of the Study}

The purpose of this research is constructing a mechanism, that supports the reduction of abandoned agriculture lands, such as including prioritization when selecting abandoned agriculture lands and priority when reusing abandoned agriculture lands. In addition, the farmland solar radiation DB is designed to build an farmland $\mathrm{DB}$, that can manage items such as precipitation, temperature and soil in addition to solar radiation, assuming a mechanism to be able to propose crops grown using AI (Artificial Intelligence) in the future.

\section{Materials and Methods}

Overview of solar radiation simulation system using GIS and DSM

GIS is a technology that can create, manage, represent, search, analyze and share geospatial information [6]. Data used in GIS is called geospatial information (geospatial data). Geospatial data is divided into two types, raster data and vector data, depending on how the components of the real world are abstracted and represented. The raster data is a data format suitable for expressing a phenomenon in which the space continuously changes and a situation where the boundary is not clear. The vector data is a data format suitable for expressing features with clear positions and boundaries. The vector data is divided into 1 . points, 2 . lines and 3. polygons.

So far, our research team has constructed a solar radiation simulation system using GIS and DSM. DSM is elevation data, that can be used on GIS. DSM is an elevation model with elevations of buildings and trees. Another elevation model is the DEM, which has only the height of the land. Figure 1 shows the difference between DSM and DEM. As it can be seen from figure 1, when DSM is used, it is possible to analyze solar radiation simulation in consideration of the shadows of buildings and trees. In addition, a solar radiation map is created as a result. Figure 2 shows the solar radiation map.
In figure 2, a red zone indicates area with a large amount of solar radiation, and a blue zone indicates area with a small amount of solar radiation [4]. The color of the solar radiation map in this study is the same.

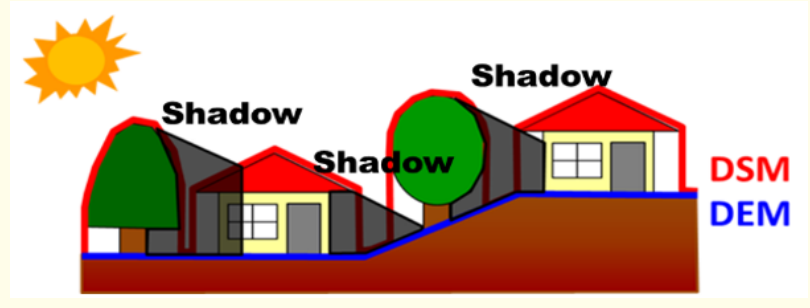

Figure 1: The difference between DSM and DEM.

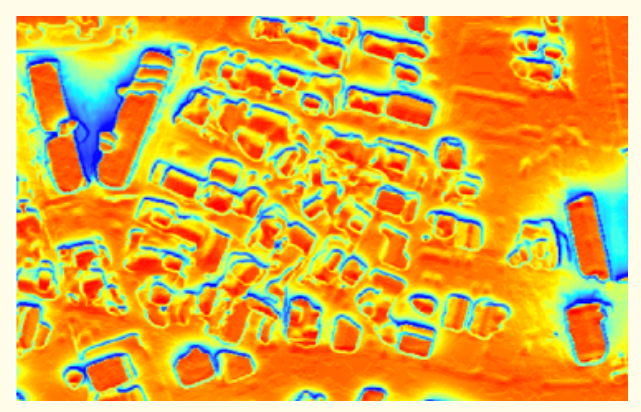

Figure 2: Solar radiation map.

System overview

The proposed model using GIS constructed in this research consists of the following six functions. Figure 3 shows a functional flow diagram:

1. Function to analyze solar radiation in the area.

2. Function to correct solar radiation analysis results with NEDO's solar radiation DB.

3. Function to convert corrected solar radiation analysis results to point data.

4. Function to create farmland polygon data while viewing aerial photos.

5. Function to extract solar radiation point data using farmland polygon data.

6. Function to calculate average solar radiation for each farmland polygon from solar radiation point data.

\section{Research scope}

In this research, the area between Yahata Nishi Ward, Kitakyushu City and Nogata City in Fukuoka Prefecture, Japan is a demonstration area. Figure 4 shows the demonstration area. The demonstration area, which plains and mountains have included is 


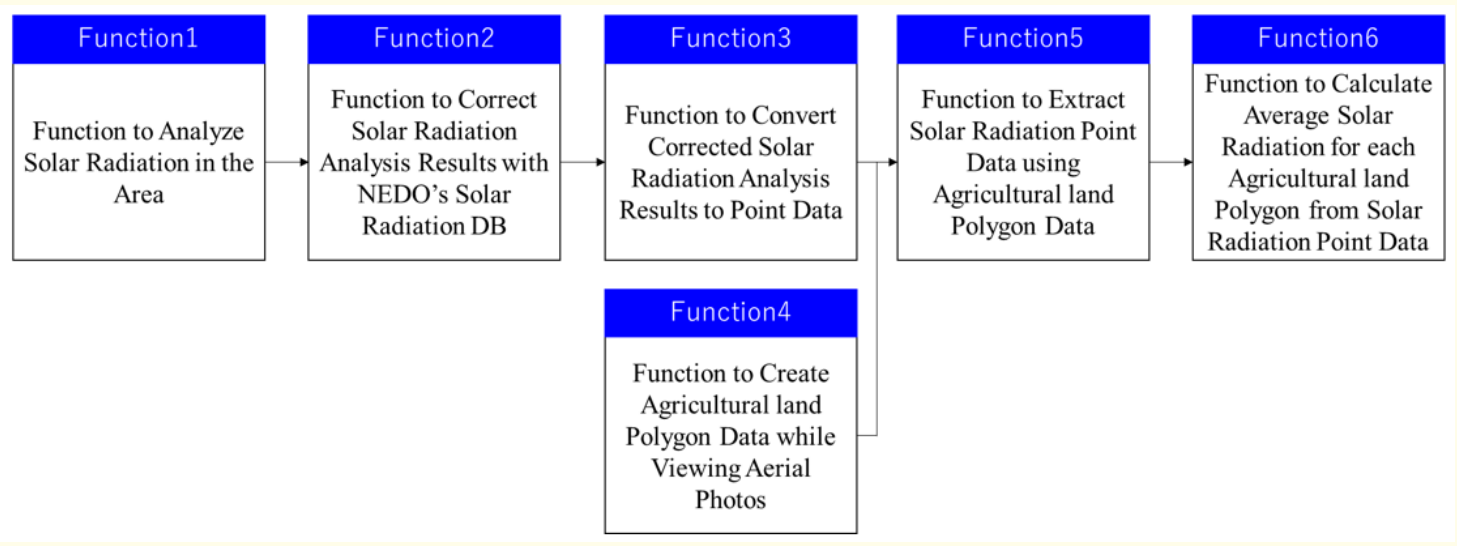

Figure 3: Function of the model and flowchart diagram.

the east-west direction about $4 \mathrm{~km}$, an area of about $2.6 \mathrm{~km}$ northsouth direction. The plains are widespread fields and paddy fields, there is a small hill in the part. There are some fields and paddy fields in the residential area. The fields and paddy fields are also spreading in the mountains.

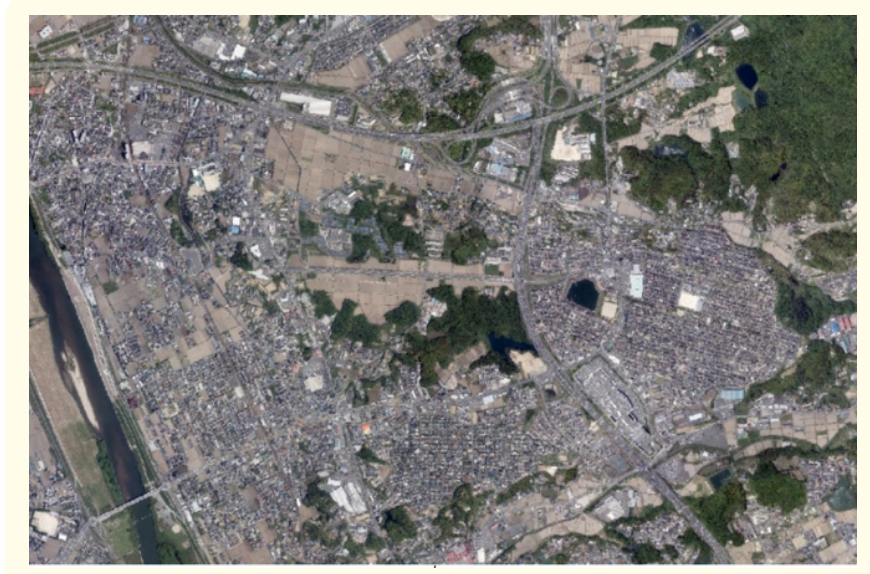

Figure 4: Demonstration area.

Function to analyze solar radiation in the area (Function 1)

This function uses aerial photographs and DSMs owned by local governments. Therefore, when performing solar radiation analysis, 1. it takes enormous time to process all areas of the local government, 2. the processing may not be possible due to lack of computer memory. Since high-speed processing is required [7] when a service is started in the future, it is necessary to extract a target area. In order to extract it, it is necessary to draw a polygon of a necessary area as a first process. As a second process, it is used the GIS Clip function to cut out polygons depicting aerial photograph and DSM. Figure 5 shows the above processing steps and processing results. In figure 5 , a blue polygon on the aerial photograph shows a target area to be extracted.

Next, solar radiation analysis processing is performed on the extracted area. This process uses the results of previous research in the electric power field. The analysis processing was performed by setting the scattering factor of 0.3 and the transmittance of 0.5 on the GIS (the weather condition is generally sunny). In this research, in order to store more detailed solar irradiance when creat-

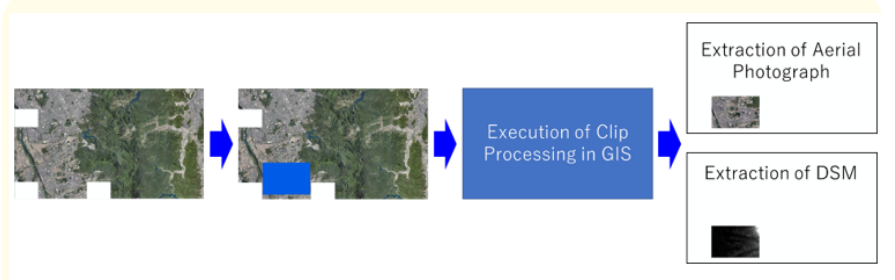

Figure 5: Overview of the extraction of the required area.

ing a farmland DB, it is analyzed the amount of annual solar radiation and the amount of solar radiation in each month from January to December. In addition, assuming the target crop is fixed, thus, it has been developed with a mechanism, that can perform solar radiation analysis for a limited period. Figure 6 shows the analysis results of the annual solar radiation $\left(\mathrm{Wh} / \mathrm{m}^{2}\right)$.

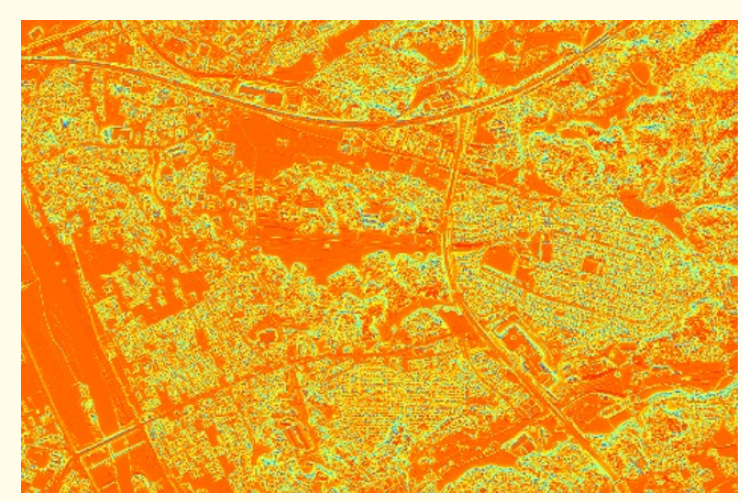

Figure 6: Annual solar radiation.

Function to correct solar radiation analysis results with NEDO's solar radiation DB (Function 2)

In the results of solar radiation analysis created by Function 1 , the weather condition is fixed to sunny. Therefore, to grasp the amount of solar radiation that actually falls on farmland, it is necessary to consider the factors of the weather change. Therefore, in this function, the analysis result of Function 1 is corrected using the value of the "National Solar Radiation Map" held by the New Energy and Industrial Technology Development Organization (NEDO). In previous research, a horizontal plane was created in 
the target area using GIS, and the amount of solar radiation on the horizontal plane was analyzed [8]. A correcting method was used in which the ratio was obtained from the results of the solar radiation analysis on the horizontal plane and the value of the global solar radiation on the NEDO's national solar radiation map, then the ratio was multiplied by the result of the solar radiation analysis. In this research, to obtain the high efficiency, the correction has been performed using the optimal tilt angle solar radiation on the national solar radiation map. Specifically, it is used a method to calculate the ratio from the maximum value of the solar radiation in the solar radiation analysis result of Function 1, and the value of the optimal tilt angle solar radiation in the NEDO's national solar radiation map, and multiply the ratio by the solar radiation analysis result. Figure 7 shows the flow chart between the conventional method and the proposed method. In this research, it is corrected the annual solar radiation $\left(\mathrm{Wh} / \mathrm{m}^{2}\right)$ and monthly solar radiation $\left(\mathrm{Wh} / \mathrm{m}^{2}\right)$. This method also incorporated with the contrastive weather conditions into the solar radiation map. Figure 8 shows a comparison of the annual solar radiation maps before and after the correction. Figure 9 shows the solar radiation maps for each month before and after the correction.
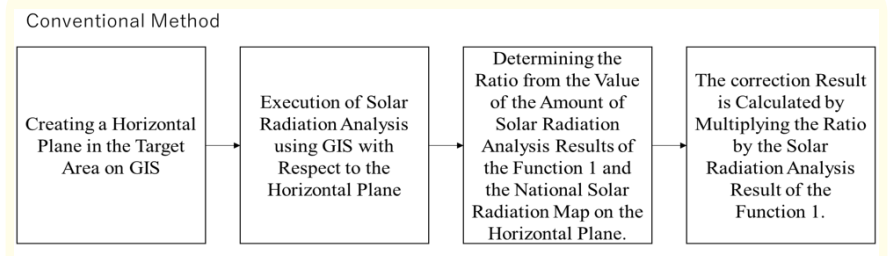

Method Used in this Research

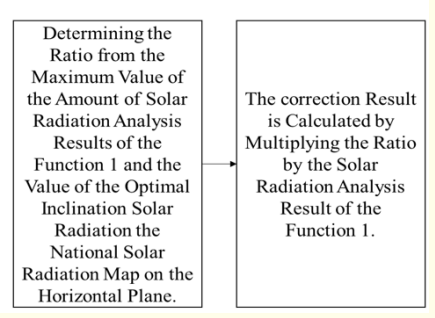

Figure 7: Comparison of processing flowcharts.

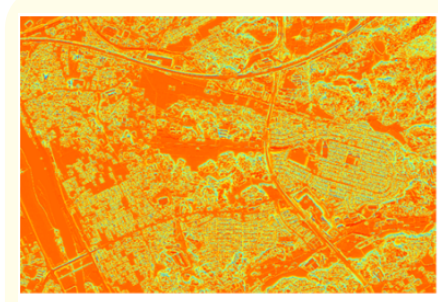

(a) Before Correction

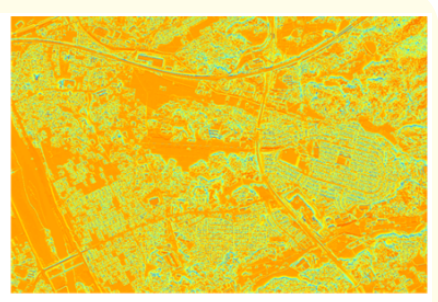

(b) After Correction
Figure 8: Comparison before and after correction (Annual Solar Radiation).

Function to convert corrected solar radiation analysis results to point data (Function 3)

The purpose of this research is to construct a database of the amount of solar radiation, that ultimately falls on each farmland. The details are shown in 5.7 and the farmland is created by poly-
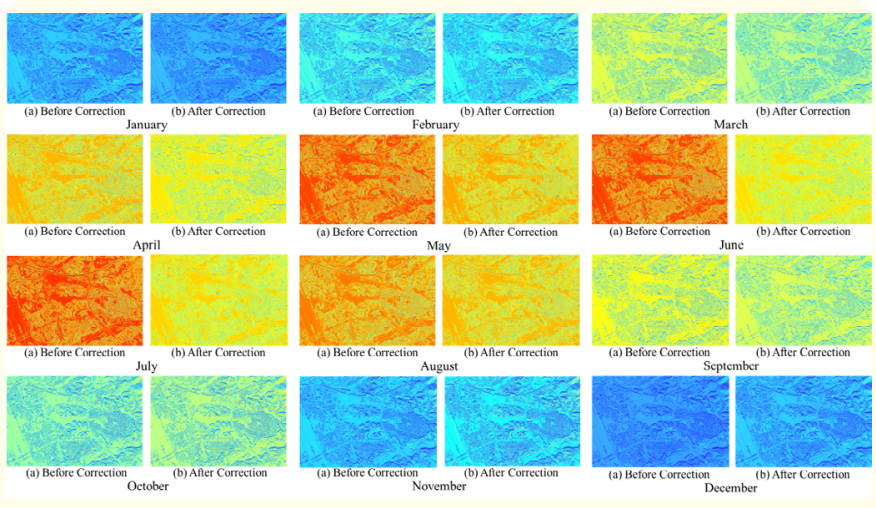

Figure 9: Comparison before and after correction

(Monthly Solar Radiation).

gon data. The result of the solar radiation analysis taking into account the weather conditions created by the function 2 is the raster data. In this research, it is used the ArcGIS software. However, in ArcGIS, the raster data values cannot be directly aggregated into polygon data. Therefore, it is necessary to convert the raster data into the point data, and to aggregate the point data with the polygon data. Therefore, the function 3 is a function for performing a process of converting raster data to point data. To convert raster data to point data, use "Raster to Polygon" the ArcGIS Conversion Toolbox is used. The solar radiation map created by the function 2 in consideration of the weather conditions is raster data, and it has a solar radiation value $\left(\mathrm{Wh} / \mathrm{m}^{2}\right)$ for each mesh. When the "Raster to Polygon" process is performed, a point is created at the center of gravity of the mesh of the raster data, and the solar radiation value is stored as attribute information at the point. Figure 10 shows the result of conversion from raster data to point data including superimposition. In figure 10 , the colors of the raster data and the points are such red area, which indicates a large amount of solar radiation. The blue area indicates a small amount of solar radiation. It is possible to see that one point has been created on the raster mesh.

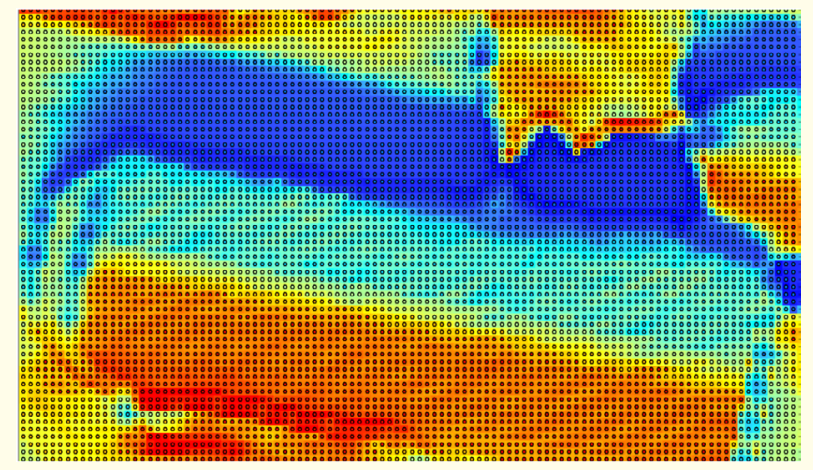

Figure 10: The result of superimposing solar radiation raster and points (January).

Function to create farmland polygon data while viewing aerial photos (Function 4)

This function uses the polygon drawing function in ArcGIS. It is constructed a mechanism that user can draw polygons on the 
farmland using an aerial photograph as a base map. Furthermore, it has been constructed a mechanism in which when farmland polygons are drawn, the area of the farmland is calculated and stored in the DB. This function is designed so that when a local government or the like has farmland polygons, the farmland polygons can be imported. In this research, it has been drawn 1,825 farmland polygons in the demonstration area. It took about 18 hours to draw. It has been discovered that it is necessary to construct a function to interpret farmland from aerial photographs using AI to create polygons. Figure 11 shows the farmland polygon drawn on the aerial photograph. The pink surface is the farmland polygon. Figure 12 shows an attribute table of the farmland polygon. It is indicated that there are 1825 farmland polygons from the numerical value surrounded by the red square.

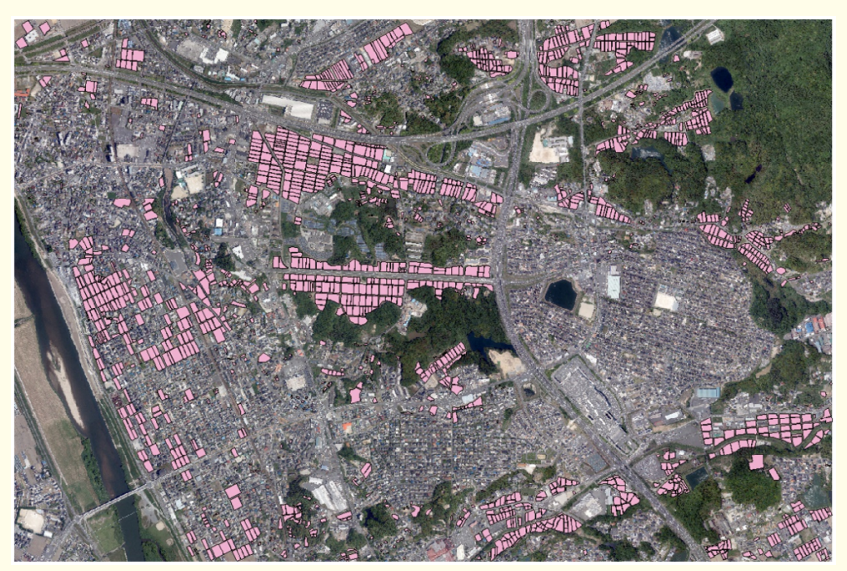

Figure 11: The farmland polygons.

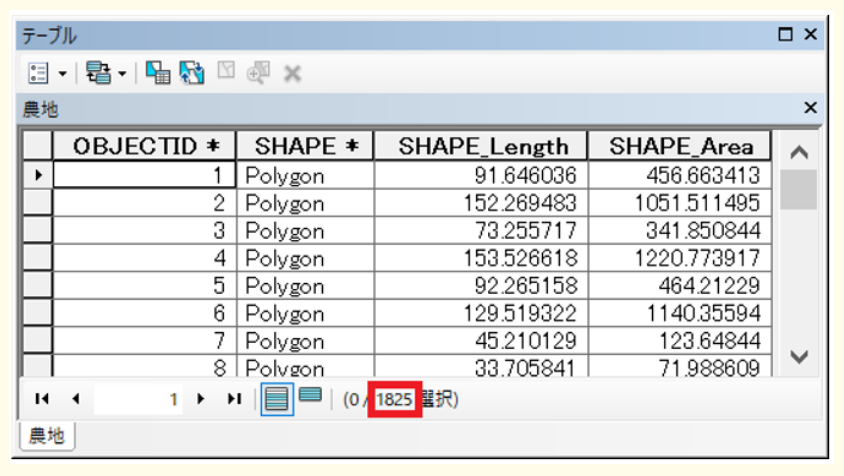

Figure 12: The attribute table of farmland polygon.

Function to extract solar radiation point data using farmland polygon data (Function 5)

The DSM used in this research has an accuracy of $50 \mathrm{~cm} \times 50$ $\mathrm{cm}$ mesh. Therefore, the solar radiation map, which is the result of the solar radiation analysis, has the same accuracy. So, the point data as the output result of the function 4 is created every $50 \mathrm{~cm}$. If the process of summarizing the amount of solar radiation on farmland polygons was performed for the point data of the entire demonstration area, there was a problem that processing errors occurred due to insufficient memory of computers due to too much data to be handled, and processing could not be performed. Therefore, this function solves the above-mentioned problem by reduc- ing the amount of data to be handled when counting with farmland polygons. Specifically, the solar radiation points on the farmland polygon are extracted. It is used the clip function of GIS to extract solar radiation points that overlap farmland polygons. Figure 13 shows a positional relationship diagram between the solar radiation points on the farmland polygon and the solar radiation points outside the farmland polygon. In figure 13 , the pink surface represents farmland. Blue points represent solar radiation points on farmland polygons. Red points represent solar radiation points that are not on farmland polygons. The right view is an enlarged view inside the black frame in the left view. The positional relationship between the farmland polygons and the solar radiation points can be confirmed in the right figure. Figure 14 shows the results of the part of clips in the demonstration area.

In figure 14, the left figure shows farmland polygons in the demonstration area, and the right figure shows extracted solar radiation points. In the right diagram of figure 14 , the color shows the magnitude of the amount of solar radiation $\left(\mathrm{Wh} / \mathrm{m}^{2}\right)$, the red color indicates that the amount of solar radiation is large and the blue color indicates that the amount of solar radiation is small. From the above, it has been possible to extract solar radiation points on farmland polygons.
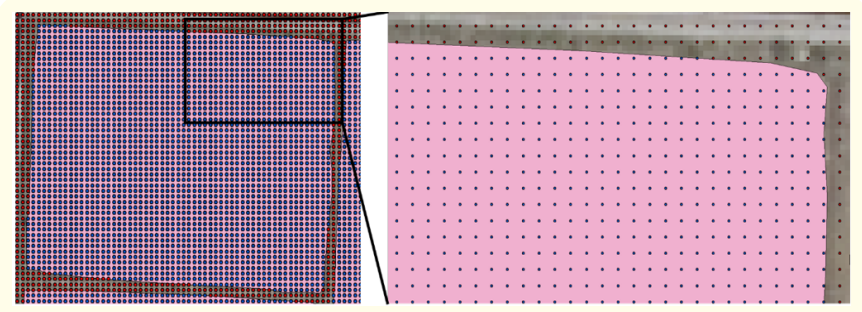

Figure 13: The diagram of the positional relationship between farmland polygons and solar radiation points.

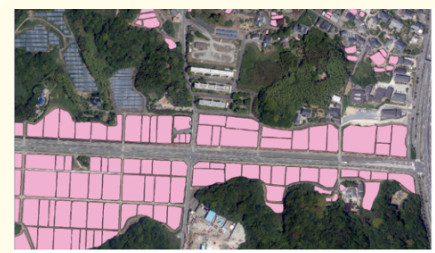

(a) Farmland Polygon

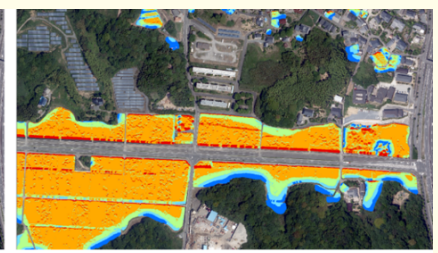

(b) Result of Clip
Figure 14: The result of clip.

Function to calculate average solar radiation for each farmland polygon from solar radiation point data (Function 6)

In this function, the solar radiation point data on the farmland polygon is aggregated by the farmland polygon. The GIS function used in this function is spatial join processing. In the spatial join processing, the target feature is farmland polygons, the joined feature is solar radiation points, the aggregation item is the amount of solar radiation, and the aggregated method is the calculation of an average value. As a result, the annual and monthly solar radiation amounts have been stored in the attribute information of the farmland polygon. Figure 15 shows the aggregated result. In figure 
15 , the color shows the magnitude of the annual solar radiation $\left(\mathrm{Wh} / \mathrm{m}^{2}\right)$ for each farmland, the red color shows large and the blue color shows small. From figure $15 \mathrm{~b}$, it is possible to see that the farmlands of blue, light blue, green, yellow, etc. have mountains, trees, buildings, etc. in the surrounding area and they are affected by their shadows. Next, each farmland polygon having the solar radiation amount for year and each month as attribute information is subjected to a table joining process. By this processing, the annual solar radiation and the monthly solar radiation have been consolidated into the attribute information of the farmland polygon. Based on the above, it has been constructed a farmland solar radiation DB that stores annual and monthly solar radiation for each farmland. The items of the farmland solar radiation DB are shown in figure 16. The DB items are for farmland surrounded by black frames.

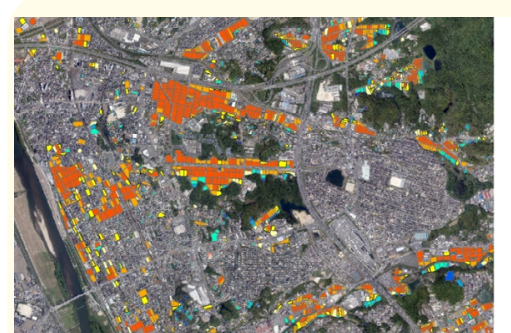

(a) Demonstration area overview (b) Enlarged view

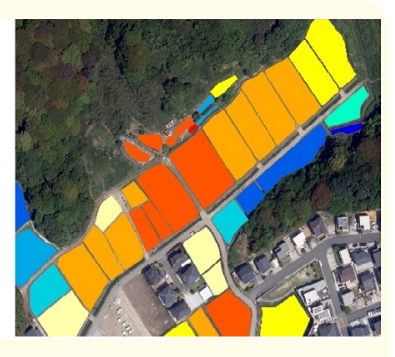

Figure 15: The Farmland polygons with solar radiation (annual).

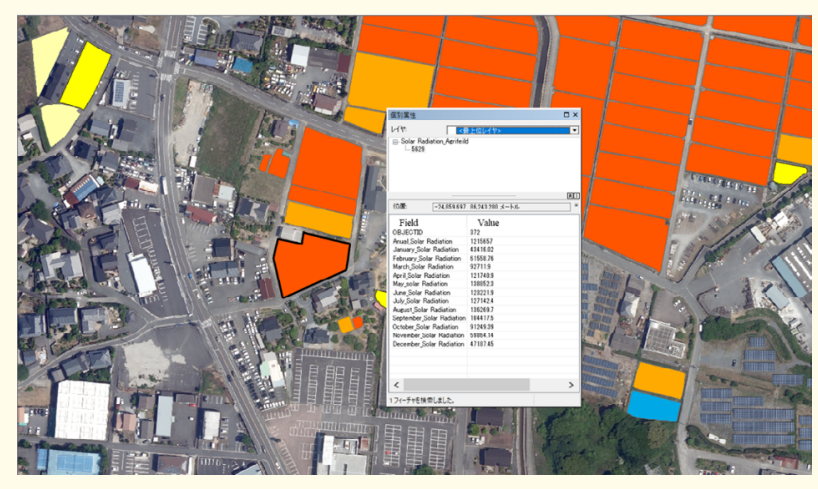

Figure 16: The Farmland polygons with solar radiation DB.

At this point, the items of the farmland solar radiation DB are loaded with annual and monthly solar radiation. However, these items are designed to store data such as soil, temperature, and precipitation and so on.

The maximum annual solar radiation in the farmland solar radiation DB in the demonstration area of this research is about $1,270,843.125\left(\mathrm{Wh} / \mathrm{m}^{2}\right)$. Table 1 shows the ratio of the annual amount of solar radiation in the farmland solar radiation DB from the maximum value, the number of corresponding farmlands, and the total area. It is assumed that abandoned cultivated land will be selected because it is not possible to secure workers. Using table 1 , it can be seen that, for example, if the farmland is about $60 \%$ or less of the maximum value, 14 locations can be selected, and the area is about 2802.568035 square meters. The advantage of using GIS is that it is possible to understand the area in this way.

\begin{tabular}{|l|c|c|c|}
\hline No & $\begin{array}{c}\text { Percentage from } \\
\text { Maximum Value }\end{array}$ & $\begin{array}{c}\text { The number } \\
\text { of farmlands }\end{array}$ & $\begin{array}{c}\text { Area of farmlands } \\
{\left[\mathbf{m}^{2}\right]}\end{array}$ \\
\hline 1 & $90 \%$ or less & 490 & 167357.3488 \\
\hline 2 & $80 \%$ or less & 143 & 36073.91931 \\
\hline 3 & $70 \%$ or less & 45 & 9401.815274 \\
\hline 4 & $60 \%$ or less & 14 & 2802.568035 \\
\hline 5 & $50 \%$ or less & 2 & 367.4921062 \\
\hline 6 & $40 \%$ or less & 0 & 0 \\
\hline
\end{tabular}

Table 1: Percentage of the annual average insolation DB in the farmland solar radiation DB from the maximum value and the number of corresponding farmlands.

\section{Results and Discussion}

In this research, it is focused on the fact that the larger integrated amount of received light, the larger amount of dry matter produced. Then, it has been constructed the farmland solar radiation DB that can be used to address the problem of abandoned agriculture land. Specifically, when abandoned agriculture land is inevitably generated, it has become possible to preferentially set such agriculture land from farmland with a low amount of solar radiation that falls. Also, when abandoned agriculture land is reused, it has become possible to preferentially reuse farmland that has a large amount of insolation.

Furthermore, in this research, it is used GIS, so the area is acquired when the farmland polygons are drawn. In Japan, when the government implements the measures, the area of farmland may be indicated as a target for the reuse of abandoned agriculture land. Even in that case, the area can be calculated for each amount of solar radiation.

In the future, to promote the reuse of abandoned agriculture land and encourage young people to start farming, it is necessary to build a system that can use AI to propose crops suitable for each farmland. Therefore, it is necessary to develop a DB, that incorporates information necessary for producing crops, such as soil, temperature, soil temperature, and precipitation in the farmland solar radiation DB as constructed in this research.

\section{Conclusion}

In Japan, abandoned arable land continues to increase due to labor shortages and other problems. Although there is a difference between crops, it is known that the larger integrated light receiving amount, the larger dry matter production. In this research, it has been constructed farmland solar radiation DB, that can manage the amount of solar radiation of falling on each farmland to determine the shadows of buildings and trees and weather conditions by applying the solar radiation simulation technology, that has been established in the field of electric energy. As a result, it has become possible to visualize farmland, that can obtain a large amount of solar radiation and indicate the prioritization when selecting abandoned agriculture land and the priority when reusing abandoned agriculture land. In other words, it has been possible to construct a system to support reduction of abandoned agriculture land. From the above, the purpose of this research has been achieved. 
In the future, our research team plan to further develop the farmland solar radiation DB constructed in this research to include the new data, such as soil, temperature, soil temperature, and precipitation. With this, it is planned to build a system that can propose suitable crops for each farmland to farmers by using AI.

\section{Acknowledgements}

I would like to thank the staffs of Kitakyushu city who provided some data for this research. I also thank you for all students in the laboratory at Kyushu Institute of Technology, who carried out research together.

\section{Conflict of Interest}

I have no economic interests or conflicts of interest.

\section{Bibliography}

1. "Current status and issues of abandoned cultivated land". Ministry of Agriculture, Forestry and Fisheries (2007).

2. "Changes in farmland and abandoned land area". Cabinet Office (2016).

3. Tatsuhiko Shiraiwa., et al. "Estimation of solar radiation efficiency of crop". Japanese Journal of Crop Science 80.3 (2011): 360-364.

4. Atsushi Shiota., et al. "Development and Public Release of Solar Radiation Map for Effective Use of Solar Energy Based on GIS with Digital Surface Model”. CPESE (2015).

5. Atsushi Shiota., et al. "GIS Utilization to Support the Application of Supplying Electric Power to Temporary Housing with PV and Energy Storage". In Proceedings International Conference on Electrical Engineering (ICEE) (2016).

6. Atsushi Shiota., et al. "Construction of Solar Radiation Simulation Database and Solar Radiation Simulation System using GIS and Application to the Agriculture Field". Acta Scientific Agriculture 3.10 (2019): 2-9.

7. A Shiota., et al. "Sharing Regional Information with Spatial Information between Public and Proactive Citizens Based on Technology of Hybrid Cloud - Contribution for Disaster Reduction by G-motty of city of Kitakyushu". Geospatial Information \& Technology Association (GITA) (2015).

8. Atsushi Shiota. "Research on Application of Geographic Information System (GIS) to Electric Power and Energy Field and Contribution to the Society with Disaster Prevention and Mitigation". Doctor's thesis at Kyushu Institute of Technology, Japan (2017).

\section{Assets from publication with us}

- Prompt Acknowledgement after receiving the article

- Thorough Double blinded peer review

- Rapid Publication

- Issue of Publication Certificate

- High visibility of your Published work

Website: www.actascientific.com/

Submit Article: www.actascientific.com/submission.php Email us: editor@actascientific.com

Contact us: +919182824667 